\title{
ROLE OF DIAGNOSTIC HYSTEROLAPAROSCOPY IN EVALUATION OF PRIMARY AND SECONDARY INFERTILITY
}

\author{
Dhananjaya Shobha ${ }^{1}$, K. N. Madhu², Agrawal Amiti ${ }^{3}$
}

\section{HOW TO CITE THIS ARTICLE:}

Dhananjaya Shobha, K. N. Madhu, Agrawal Amiti. "Role of Diagnostic Hysterolaparoscopy in Evaluation of Primary and Secondary Infertility". Journal of Evolution of Medical and Dental Sciences 2014; Vol. 3, Issue 09, March 3; Page: 2194-2207, DOI: 10.14260/jemds/2014/2126

ABSTRACT: BACKGROUND AND OBJECTIVES: Laparoscopy is considered the gold standard for diagnosing tubal and peritoneal disease. The present study was aimed to evaluate the role of hysterolaparoscopy in the study of primary and secondary infertility so as to identify the various pathological conditions in female reproductive tract leading to primary/ secondary infertility and also to observe the complications of the procedure. METHODOLOGY: The present one year observational study was done in the Department of Obstetrics and Gynecology of a tertiary care hospital situated in Davanagere, Karnataka from January 2012 to December 2012. A total of 100 infertile women, anxious to conceive, coming for infertility work-up in hospitals underwent hysterolaparoscopy. RESULTS: The commonest age group was 26 to 30 years (57\%) and the mean age was $27.27 \pm 3.59$ years. The history of consanguineous marriage was present in $20 \%$. Majority (74\%) of the women reported regular cycles while $26 \%$ of the women reported irregular menstrual history. Almost half of the study population (50\%) had duration of infertility between 4 to 6 years and the mean duration was $4.62 \pm 158$ years. Primary infertility was noted in $79 \%$ of the women and PCOS was the commonest finding noted in $18.99 \%$. In women with secondary infertility, pelvic inflammatory disease was the commonest diagnosis (19.05\%). Majority $(96.20 \%$ and $90.48 \%$ respectively) of the women with primary and secondary infertility did not have any complications. CONCLUSION AND INTERPRETATION: Diagnostic hysterolaparoscopy identifies the various pathological conditions leading to primary and secondary infertility and thus helps obstetrician for effective management hence it may be performed in all infertile patients.

KEYWORDS: Hysterolaparoscopy; Hysteroscopy; Infertility; Primary infertility; Secondary infertility.

INTRODUCTION: Historically the human race has placed emphasis on infertility. Nothing more vividly demonstrates the importance of fertility to individual than the reaction by and to those who do not have children. It is estimated that, approximately $8-10 \%$ of couples are childless against the wishes of the partners which makes it as a common problem. ${ }^{1}$

According to the International Committee for Monitoring Assisted Reproductive Technology and the World Health Organization, infertility is a disease of the reproductive system defined by the failure to achieve a clinical pregnancy after 12 months or more of regular unprotected sexual intercourse'.2

Global estimates suggest that nearly 72.4 million couples experience fertility problems. ${ }^{2}$ World health organization estimates in 2010 reported that, $1.9 \%$ of women aged $20-44$ years who wanted to have children were unable to have their first live birth (primary infertility) and 10.5\% with a previous live birth were unable to have an additional live birth (secondary infertility). The levels of infertility were similar in 1990 and 2010, with only a slight overall decrease in primary infertility ( $0.1 \%$, but with a more pronounced drop in Sub-Saharan Africa and South Asia) and a modest overall 


\section{ORIGINAL ARTICLE}

increase in secondary infertility $(0.4 \%)$. The prevalence of primary infertility was higher among women aged 20-24 years than among older women. Primary infertility rates among women wanting children also varied by region, from $1.5 \%$ in Latin America and the Caribbean in 2010, to 2.6\% in North Africa and the Middle East. With a few exceptions, global and country patterns of secondary infertility were similar to those of primary infertility. ${ }^{3}$

The prevalence of infertility ranges from $3.5 \%$ to $16.7 \%$ in more developed nations and from $6.9 \%$ to $9.3 \%$ in less developed nations, with an estimated overall median prevalence of $9 \% .{ }^{4}$ There is escalating incidence of infertility in India. According to Delhi IVF Infertility Research Centre, infertility affects one in six couples. The recent National Family Health Survey (NFHS) estimates showed that, childlessness in $2.4 \%$ of currently married women aged over 40 years. $^{5}$

Infertility is caused by male and/or female factors. Female factor infertility can be divided into several categories: cervical or uterine, ovarian, tubal, and other. ${ }^{6}$ The diagnosis and treatment of this disorder stands out as one of the most rapidly evolving area in medicine. Experience has shown that majority of pelvic pathology in infertile women is frequently not well appreciated by routine pelvic examinations and the usual diagnostic procedures. ${ }^{3}$ Infertility is generally a tragedy to the couple and brings forth family unhappiness and mental dysharmony. Hence it's the responsibility of the gynecologist to make a correct diagnosis of the cause of infertility and plan the treatment protocol accordingly. A complete examination of a woman's internal pelvic structures can provide important information regarding infertility and common gynecologic disorders. ${ }^{7}$

Hystero-laparoscopy becomes the "Third eye of the gynecologist" in diagnosis of infertility. Frequently, problems that cannot be discovered by an external physical examination can be discovered by laparoscopy and hysteroscopy, two procedures that provide a direct look at the pelvic organs. These procedures may be recommended as part of your infertility care, depending on your particular situation. Laparoscopy and hysteroscopy can be used for both diagnostic (looking only) and operative (looking and treating) purposes. ${ }^{7}$ The ability to see and manipulate the uterus, fallopian tubes, and ovaries during laparoscopy has made it an essential part of infertility evaluation. Similarly, visualizing the uterine cavity and identifying the possible pathology has made hysteroscopy an equally important tool in infertility evaluation. The question of tubal morphology and patency, ovarian morphology, any unsuspected pelvic pathology, and uterine cavity abnormalities can all be resolved with accuracy at one session. Additionally, hysteroscopic guided biopsy and therapeutic procedures like polypectomy, myomectomy, septal resection, and adhesiolysis can be done in the same sitting. ${ }^{3}$

Studies have shown that diagnostic laparoscopy and diagnostic hysteroscopy are effective procedures for evaluation of long term infertility. ${ }^{8}$ In infertile couples laparoscopy reveals abnormal findings in $21.68 \%$ of cases after normal hysterosalpingography. ${ }^{9}$ Also, diagnostic hysteroscopy is a very important method for investigation of the reasons of female infertility. ${ }^{10}$ Hystero-laparoscopy is a quintessential tool for the diagnosis, treatment and prognosis as it allows the gynecologist to develop the plan of therapy in infertile patients. However, to date, few studies have assessed the role of combined diagnostic laparoscopy and simultaneous diagnostic hysteroscopy in cases of female infertility and no such study was undertaken in our settings using this approach. Hence the present study was planned to evaluate the role of hystero-laparoscopy in the study of primary and secondary infertility, to identify the various pathological conditions in female reproductive tract leading to 
primary/ secondary infertility, to develop a plan for therapy and to analyze the rate of complications in diagnostic hystero-laparoscopy.

METHODOLOGY: This cross-sectional study was conducted over a period of one year in the Department of Obstetrics and Gynecology of a tertiary care center in Davanagere, Karnataka from January 2012 to December 2012. Prior to the commencement of the study, ethical clearance was obtained from Human Ethics Committee. A total of 100 Married women aged between 18 to 40 years with primary/secondary infertility who were willing for infertility workup with normal semen analysis of the husband were included in the study. Women with severe cardiac/ respiratory illness, acute generalized peritonitis, anesthetic problems, diabetes mellitus, severe anemia, sexually transmitted diseases, severe urinary tract infection and not willing for surgery were excluded.

The patients satisfying selection criteria were informed in detail about the nature of the study and a written informed consent was obtained. After the enrollment, demographic data such as age, religion, education, socio economic status, were obtained through an interview. Detailed history including complaints, married life, obstetric, sexual, menstrual, medical and pharmacological history was documented and clinical examination was performed. These findings were recorded on a predesigned and pretested proforma.

Hysterolaparoscopy was performed in the pre ovulatory period between days 6-10 of the cycle for infertility evaluation. Routine investigations such as hemoglobin percentage, blood group and Rh type, VDRL, RBS, Urine routine and microscopy, and chest X-ray were done. Specific investigations like Semen analysis were done to rule out the male factors of infertility, pelvic ultrasound and endometrial biopsy were done in some specific cases. Hysterolaparoscopy was done under general anesthesia after the opinion of the anesthetist.

Diagnostic Laparoscopy was performed using a $7 \mathrm{~mm}$ Karl Storz laparoscope with a 30 degree deflection angle telescope powered with a fibreoptic cable for light source. A careful evaluation of the fallopian tubes, ovaries, pelvic peritoneum, pouch of Douglas and peritoneal cavity was done. The features suggestive of infertility were looked for. Chromopertubation was done to see the tubal patency on both the sides. On laparoscopy, pelvic cavity and organs were inspected. Uterus was inspected for its shape, size, position and surface. Cul-de-sac was examined for any adhesions, obliteration, endometriotic nodules or fluid. Ovaries were viewed for size, shape, surface, color, presence of cysts and relation with tubes.

Fallopian tubes were inspected carefully for size, shape, surface, kinking, dilatation, stricture or hydrosalpinx. Laparoscopic chromopertubation was performed for testing tubal patency in which methylene blue dye was injected with a $20 \mathrm{ml}$ syringe via Leech Wilkinson cannula and spillage of dye from the fimbrial end of tube visualized.

On hysteroscopy, uterine cavity was examined for the presence of septum, any congenital malformation, fibrotic bands, polyps, myomas, endometrial appearance, thickness and color. Endocervical canal was visualized for any growth or polyps. Both the tubal ostia were visualized.

Statistical analysis: The data obtained was coded and entered into Microsoft Excel Worksheet. Categorical data was expressed as rates, ratios and proportions and continuous data was expressed as mean \pm standard deviation (SD). 
RESULTS: Most of the women (57\%) were aged between 26 to 30 years. The mean age of the study population was $27.27 \pm 3.59$ years. Based on kuppuswamy index $39 \%$ of the women had education upto grade IV and class III socio economic status (64\%). The menarcheal age was noted as 13 years in $52 \%$ of the women and history of consanginous marriage was present in 20\%. Majority (74\%) of the women reported regular cycles while $26 \%$ of the women reported irregular menstrual history. Almost half of the study population (50\%) had duration of infertility between 4 to 6 years followed by 3 years or less (45\%) with mean duration of infertility being $4.62 \pm 158$ years. Majority (79\%) of the women presented with primary infertility while secondary infertility was noted in $21 \%$ of the women.

On speculum examination, $85 \%$ of the women had normal cervix and 15\% women had abnormalities. Among those with abnormalities, erosion was the commonest finding noted in $12 \%$ women. Bimanual examination of the uterus revealed anteverted uterus in $80 \%$ of the women while $20 \%$ of the women had retroverted uterus. Also bulky and atrophic uterus was noted in $9 \%$ and $1 \%$ of the women respectively while mobile uterus was seen in $90 \%$ of the women and restricted mobility was observed in 10\%. With regard to fornices, full fornices were noted in $10 \%$ of the women and free fornices in $90 \%$ of the women.

The laparoscopic examination findings for size and shape of uterus included bulky, congested, hypoplastic (1.27\% each) and irregular uterus (10.13\%) in women who had primary infertility while in those with secondary infertility $4.76 \%$ of the women bulky uterus. (Graph. 1). With regard to size and shape of ovary, cystic (6.63\%), endometrial implants (2.53\%), enlarged (43.04\%) and adhesions $(1.27 \%)$ were noted in women with primary infertility and in those with secondary infertility, cystic (9.52\%), enlarged (4.76\%), atrophic (4.76\%) and adhesions (4.76\%) were observed (Graph. 2). Among the women with primary infertility, ovary color was shiny in $37.97 \%$ and pale in $2.53 \%$ of the women. In those with secondary infertility, shiny color was seen in $4.76 \%$ of the women (Table 1 ). The appearance of inflamed tubes was noted in $2.53 \%$ of women with primary infertility, compared to $19.05 \%$ women with secondary infertility. The other findings are as shown in Table 2. Left adhesion was present in one case of secondary infertility (4.76\%) while in another case the fimbria was seen $(1.27 \%)$. Chromopertubation was positive in $72.15 \%$ of women with primary infertility compared to $42.86 \%$ of the women with secondary infertility.

Subserous anterior wall was the fibroid location in $10.13 \%$ of the women with primary infertility and subserous fundal location was seen in $1.27 \%$ but, in women with secondary infertility, subserous anterior wall was observed in $4.76 \%$ and none of the women had latter location. Endometrial implant adhesions were positive in $10.13 \%$ of the women with primary infertility compared to $9.52 \%$ women who had secondary infertility. Peritoneal findings on laparoscopy included tubercles on ovary, tubes and peritoneum, omental adhesions and grade I endometriosis in $2.53 \%$ cases each and hydatid cyst of morgagni was present in $1.27 \%$ cases with primary infertility. In those with secondary infertility, 9.52\% each had tubercles on ovary, tubes and peritoneum, and grade I endometriosis, hydatid cyst of morgagni was present in $4.76 \%$ (Table. 3 ).

The commonest hysteroscopic uterine cavity abnormality in primary and secondary infertility was endometrial polyp seen in $10.13 \%$ and $19.05 \%$ of the women respectively. The other hysteroscopic uterine cavity abnormalities are as shown in graph 3. Ostial abnormalities of corneal adhesions were present in women with secondary infertility $(9.52 \%)$ while none of the women with primary infertility had ostial abnormalities. Table 4 shows the final diagnosis of the women evaluated 
on hysterolaparoscopy. In women primary infertility PCOS was the commonest finding noted in 18.99\% while in those with secondary infertility pelvic inflammatory disease was the commonest diagnosis noted in $19.05 \%$ women. Majority of the women with primary and secondary infertility did not have any complications (96.20\% and 90.48\% respectively) (Table 5).

DISCUSSION: Laparoscopy is considered the gold standard for diagnosing tubal and peritoneal disease. It is transperitoneal endoscopic technique that provides direct visualization of pelvis and complete view of cul-de-sac, pelvic side walls and all pelvic viscera. Hysteroscopy is a procedure that involves insertion of an endoscope through the cervical canal into the uterine cavity and instillation of distention media to allow for visualization. ${ }^{11}$

In the present study the commonest age groups was 26 to 30 years (57\%). The mean age of the study population was $27.27 \pm 3.59$ years. Kore $S$ et al, 12 in their study reported similar observation where most of the women studied were between 25-30 years of age. In the present study, the history of consanguineous marriage was noted in 20\%. The menarcheal age in 52\% of the women was 13 years. Majority (74\%) of the women reported regular cycles while $26 \%$ of the women reported irregular menstrual history.

Almost half of the study population (50\%) had duration of infertility between 4 to 6 years followed by $45 \%$ women with 3 years or less. The mean duration of infertility was $4.62 \pm 158$ years. Majority (79\%) of the women presented with primary infertility while secondary infertility was noted in $21 \%$ of the women. Kore $\mathrm{S}$ et al, 12 in their study reported 34 patients had primary infertility and 6 had secondary infertility. Similarly Nayak PK et al ${ }^{13}$ from Odisha conducted a retrospective study to determine the role of diagnostic hysterolaparoscopy in the evaluation of infertility in tertiary care centres. Out of 300 cases, 206 (69\%) patients had primary infertility.

Laparoscopic examination findings for size and shape of uterus included bulky, congested, hypoplastic (1.27\% each) and irregular uterus (10.13\%) in women who had primary infertility while in those with secondary infertility $4.76 \%$ of the women bulky uterus. Findings for size and shape of ovary included cystic (6.63\%), endometrial implants $(2.53 \%)$, enlarged (43.04\%) and adhesions $(1.27 \%)$ in women with primary infertility and in those with secondary infertility, cystic (9.52\%), enlarged (4.76\%), atrophic (4.76\%) and adhesions (4.76\%) were observed. Among the women with primary infertility, ovary color was shiny in $37.97 \%$ and pale in $2.53 \%$ of the women and in those with secondary infertility, shiny color was seen in $4.76 \%$ of the women.

The appearance of inflamed tubes was noted in $2.53 \%$ of women with primary infertility compared to $19.05 \%$ women with secondary infertility. Left adhesion was noted in one case of secondary infertility (4.76\%) while in another case the fimbria was not seen (1.27\%). Chromopertubation was positive in $72.15 \%$ of women with primary infertility compared to $42.86 \%$ of the women with secondary infertility. $10.13 \%$ of the women with primary infertility had subserous anterior wall as the fibroid location and subserous fundal location was seen in $1.27 \%$ but, in women with secondary infertility, the previous location was observed in $4.76 \%$ and none of the women had latter location. Endometrial implant adhesions were positive in $10.13 \%$ of the women with primary infertility compared to $9.52 \%$ women who had secondary infertility.

The peritoneal findings on laparoscopy included tubercles on ovary, tubes and peritoneum, omental adhesions and grade I endometriosis in $2.53 \%$ cases each and hydatid cyst of morgagni was present in $1.27 \%$ cases with primary infertility. In women with secondary infertility, $9.52 \%$ each had 
tubercles on ovary, tubes and peritoneum, and grade I endometriosis, hydatid cyst of morgagni was present in $4.76 \%$. In the present study the commonest hysteroscopic uterine cavity abnormality in primary and secondary infertility was endometrial polyp seen in $10.13 \%$ and $19.05 \%$ of the women respectively. The ostial abnormalities of corneal adhesions were present in women with secondary infertility $(9.52 \%)$ while none of the women with primary infertility had ostial abnormalities.

In the present study women primary infertility PCOS was the commonest finding noted in $18.99 \%$ while in those with secondary infertility pelvic inflammatory disease was the commonest diagnosis noted in $19.05 \%$ women. The other diagnosis in women with primary infertility included Uterine fibroid (10.13\%), Endometriosis (6.33\%), PID, Ovarian cyst (3.80\% each), Endometrial polyp, PCOS with PID, Pelvic TB, Tubal block with PCOS (2.53\% each), Unicornuate uterus, Fibroid with tubal block, Fimbrial cyst with hypoplastic uterus, Hydatid cyst of morgagni, Arcuate uterus, $1.27 \%$ each) while $40.51 \%$ of the women had normal findings. The other diagnosis in women with secondary infertility included Endometrial polyp (14.29\%), Uterine fibroid, Ovarian cyst (9.52\% each), Arcuate uterus (4.76\% each) and $42.86 \%$ of the women had normal findings.

In a study by Sing R. et al ${ }^{11}$ laparoscopy abnormalities were found in $68 \%$ patients. Peritoneal adhesions (29\%) and polycystic/multicystic ovaries (26\%) were the most common findings. Other findings were phimosis/hydrosalpinx (19\%), tubo-ovarian masses (16\%), endometriosis (4\%), functional ovarian cyst (8\%), myomas (3\%) and congenital abnormalities(10\%). Sajida Parveen et al ${ }^{14}$ who reported adhesions (11.2\%), endometriosis (8\%), phimosis/hydrosalpinx (6\%), polycystic ovaries (19.35\%), functional ovarian cyst (4.8\%), myoma (4.83\%), congenital abnormalities (12.9\%), tuboovarian masses (8\%) and normal findings in $16.2 \%$, patients. Sing R. et al ${ }^{11}$ in their study reported abnormal hysteroscopy finding in $50 \%$ patients.

The most common finding was thick/irregular endometrium in $15 \%$ patients followed by intra-uterine adhesions in $11 \%$ patients .Other findings were endometrial polyps (7\%), myomas (2\%), congenital abnormalities (7\%), atrophic endometrium/ sclerotic ostia (6\%), and fetal bones embedded in endometrium (2\%). Boudhraa et al4 also reported intra-uterine adhesion (23\%), atrophic endometrium/ sclerotic ostia (7.5\%), endometrial polyp (10\%), congenital abnormalities (3.5\%), Irregular/ thick endometrium (19\%) and normal findings (25\%). Malhotra $\mathrm{N}$ et al.5 reported intra-uterine adhesions (25\%), atrophic endometrium (9.4\%) and congenital abnormalities (6.1\%). Shokeir TA, et al122 in 2006 conducted a prospective study on 612 consecutive infertile women to clarify the role of a combined diagnostic approach using laparoscopy and hysteroscopy in the evaluation of female infertility in developing countries. Laparoscopy was successful in 608 and hysteroscopy in 597 patients.

The most frequent pathologies detected hysteroscopically in the infertile group were adhesive in nature and believed to be post-traumatic and/or post-phlogistic. A significant number of women with secondary infertility had abnormal hysteroscopic findings when compared to either women with primary infertility. Boudhraa $\mathrm{K}$ et $\mathrm{al}^{15}$ in 2004 conducted a retrospective study of about 200 cases of hysterolaparoscopy performed for female infertility in women admitted at the department of Gynecology and Obstetrics in Mongi Slim's Hospital La Marsa Tunis. They concluded that hysteroscopy was abnormal in $75 \%$ of cases: the uterine synechias $(23 \%)$, endometria hypertrophy (19\%), endometrial polyps (10\%), uterine fibroids (9\%), atrophy (7.5\%) and malformations (3.5\%). Sortey KD et al ${ }^{16}$ conducted a study of 100 cases of infertility in K.E.M. Hospital, Bombay. Laparoscopic evaluation of 100 cases of infertility showed normal pelvic organs in 
$28 \%$, tubal pathology in 52\% i.e. tubal block, peritubal adhesions, tubo-ovarian mass and tuberculous salpingitis. Ovarian factors in $10 \%$ i.e., smooth ovaries, polycystic ovaries, streak ovaries and ovarian masses. In 25\% cases extensive pelvic adhesions were encountered of which 21 had previous explorations and 7 cases had TB. Other findings were fibroids, endometriosis, congenital genital abnormalities \& extensive abdominal TB.

Recently Singh R, et al11 in 2012 evaluated the role of diagnostic laparohysteroscopy in the management of infertile females. Total 100 infertile couples attending the outpatient department of obstetrics and Gynecology were selected. 60 couples belonged to primary infertility group while 40 couples belonged to secondary infertility group. All patients underwent transvaginal sonography with sonosalpingography. Then all patients were subjected to combined laparohysteroscopy including chromopertubation and the results were recorded.

The laparoscopy was abnormal in 68\% cases: Peritoneal and peri-tubal adhesions (29\%), phimosis/hydrosalpinx (19\%), polycystic ovaries (26\%), tubo-ovarian masses (16\%), endometriosis (4\%), congenital abnormalities (10\%), myomas (3\%), bilateral tubal blockage (49\%) and unilateral tubal blockage (17\%). The hysteroscopy was abnormal in 50\% cases: uterine synechias (11\%), thick endometrium (15\%), endometrial polyps (7\%), myomas (2\%), atrophy (6\%), congenital abnormalities (7\%) and fetal bones (2\%). Godinjak Z, et al ${ }^{128}$ conducted a retrospective study in 2008 to clarify the role of simultaneous combined diagnostic approach using laparoscopy and hysteroscopy in the evaluation of 360 infertile women.

Laparoscopy and hysteroscopy were successful in 360 patients. Bilateral tubes were blocked in $18(5 \%)$ and unilateral tubal occlusion were in $30(8,33 \%)$ of patients. Pelvic adhesions were revealed in $40(11,11 \%)$, and myomas in $42(11,65 \%)$ out of that $31(8,6 \%)$ were revealed by laparoscopy and $11(3,05 \%)$ by hysteroscopy. Endometrial polyps were revealed in $26(7,22 \%)$ and Syndrome Asherman in 3(0,83\%) of patients. Uterine anomaly was found in 19 (5, 27\%) of cases and out of that septate uterus in $7(37,15 \%)$, bicornuate uterus in $5(26,31 \%)$, arcuate uterus in $4(21$, $26 \%$ ) and uterus unicornu cum cornu rudimentario in $3(15,27 \%)$ of uterine anomalies. Endometriosis was found in 51(14,16\%), dermoid cysts in $8(2,22 \%)$ and in $16(4,44 \%)$ functional cysts of patients. Also, Fitz-Hugh-Curtis syndrome was revealed in $23(6,11 \%)$ patients.

More recently a retrospective study by Jayakrishnan $\mathrm{K}$ et al ${ }^{17}$ in Kerala evaluated the role of diagnostic laparoscopy in women who fail to conceive after empirical treatment with ovulation induction and intrauterine insemination. Of the 127 women who underwent diagnostic laparoscopy and hysteroscopy, $87.4 \%(n=111)$ of patients had positive findings. Significant pelvic pathology (moderate endometriosis, pelvic inflammatory disease, and tubal pathology) was seen in $26.8 \%$ of cases. Similarly Nayak PK et al ${ }^{13}$ from Odisha conducted a retrospective study to determine the role of diagnostic hysterolaparoscopy in the evaluation of infertility.

Laparoscopy detected abnormalities in $34 \%$ of the cases, significant hysteroscopy findings were noted in $18 \%$ of cases. Together, diagnostic hysterolaparoscopy detected abnormalities in $26 \%$ of the infertile patients in both groups. While the most common laparoscopic abnormality was endometriosis (14\%) and adnexal adhesion (12\%) in primary and secondary infertile patients, respectively, hysteroscopy found intrauterine septum as the most common abnormality in both groups.

In this study majority of the women with primary and secondary infertility did not had any complications (96.20\% and $90.48 \%$ respectively). Complication of hemorrhage $(2.53 \%)$ and infection 
$(1.27 \%)$ were noted in those with primary infertility while in women with secondary infertility hemorrhage was present in $4.76 \%$. Serious complications of diagnostic and operative laparoscopy are rare. The major risk is damage to the bowel, bladder, ureters, uterus, major blood vessels or other organs, which may require additional surgery.

Injuries can occur during the insertion of various instruments through the abdominal wall or during operative treatment. Certain conditions may increase the risk of serious complications. These include previous abdominal surgery, especially bowel surgery, and a history or presence of bowel/pelvic adhesions, severe endometriosis, pelvic infections, obesity, or excessive thinness. Allergic reactions, nerve damage and anesthesia complications rarely occur. Postoperative urinary retention is uncommon and venous thrombosis (blood clot) is rare. ${ }^{7}$

Overall the present study showed the usefulness of hysterolaparoscopy in the diagnosis of primary and infertility. The limitation of the study was that, we encountered various diagnosis with small proportion of patients which limited this study from establishing the association between type of infertility and commonest etiology. Further studies with large sample and with diagnosis specific evaluation would further focus the role of hysterolaparoscopy in the diagnosis and management of primary and secondary infertility.

CONCLUSION: Many diagnostic tests for female infertility have screening value but hysterolaparoscopy remains the gold standards. Based on the results of this study it be concluded that, while investigating the causes of female infertility, combined simultaneous diagnostic laparoscopy and hysteroscopy should be performed in all infertile patients before treatment.

\section{REFERENCES:}

1. Amislass, Brinden RP. A textbook of in vitro fertilization and assisted reproduction, $2^{\text {nd }}$ ed., Parthenon Publishing; 1999.

2. Gurunath S, Pandian Z, Anderson RA, Bhattacharya S. Defining infertility--a systematic review of prevalence studies. Hum Reprod Update. 2011; 17(5):575-88.

3. Mascarenhas MN, Flaxman SR, Boerma T, Vanderpoel S, Stevens GA. National, Regional, and Global Trends in Infertility Prevalence Since 1990: A Systematic Analysis of 277 Health Surveys. PLoS Med 2012; 9(12): e1001356.

4. Boivin J, Bunting L, Collins JA, Nygren KG. International estimates of infertility prevalence and treatment-seeking: potential need and demand for infertility medical care. Hum Reprod 2007; 22(6):1506-12.

5. Dutta S, Guha R. A clinicoanatomical study on the common etiological factors pertaining to primary infertility in females using some common investigative procedures. J Anat Soc India 2007; 56(2):14-7.

6. Matthiesen SM, Frederiksen Y, Ingerslev HJ, Zachariae R. Stress, distress and outcome of assisted reproductive technology (ART): a meta-analysis. Hum Reprod 2011; 26(10):2763-76.

7. Laparoscopy and hysteroscopy - A guide for patients. Alabama: American Society for Reproductive Medicine; 2012

8. Fartum M, Laufer N, Simon A. Investigations of infertile couple: Should diagnostic laparoscopy be performed after normal hysterosalpingography in treating infertility suspected to be of unknown origin? Hum Reprod 2002; 17:1-3. 
9. Sandra J, Tanahatoe GA, Cornelis B, Lamal K. Investigations of the infertile couple: Should diagnostic laparoscopy be performed in the infertility work up program in patients undergoing intrauterine insemination. Hum Reprod 2003; 18:8-11.

10. Hucke J, De Bruyme T, Balan P. Hysteroscopy in infertility - diagnosis and treatment including falloposcopy. Gynecol Obstet 2000; 20:13-20.

11. Singh R, Singh S, Yadav P, Goyal M. Role of diagnostic laparohysteroscopy in the management of infertile females. J Evolution Med Dental Sci 2013; 2(12):1792-8.

12. Shailesh K, Aparna H, Sudha N, VR Ambiye, PR Vaidya. Sonosalpingography for assessment of tubal patency: Our experience. J Obstet Gynecol Ind 2000; 50(2):63-6.

13. Nayak PK, Mahapatra PC, Mallick J, Swain S, Mitra S, Sahoo J. Role of diagnostic hysterolaparoscopy in the evaluation of infertility: A retrospective study of 300 patients. J Hum Reprod Sci 2013; 6(1):32-4.

14. Parveen S, Khanam M. Role of combined diagnostic laparoscopy and simultaneous diagnostic hysteroscopy for evaluation of female subfertility factors. J Surg Pak (International) 2010; 15(1)44-7.

15. Boudhraa K, Jellouli MA, Kassaoui O, Ben Aissia N, Ouerhani R, Triki A, Gara MF. Role of the hysteroscopy and laparoscopy in management of the female infertility: about 200 cases - J Obstet Gynaecol Res 2004; 30 (1):9-14.

16. Sortey KD Dhurandhar J. Laparoscopic evaluation of infertility - J Obstet Gynaecol India 1989; 39: 809-11.

17. Jayakrishnan K, Koshy AK, Raju R. Role of laparohysteroscopy in women with normal pelvic imaging and failed ovulation stimulation with intrauterine insemination. J Hum Reprod Sci. 2010; 3(1):20-4.

\begin{tabular}{|l|c|c|c|c|}
\hline \multirow{2}{*}{ Findings } & \multicolumn{2}{|c|}{ Primary (n=79) } & \multicolumn{2}{c|}{ Secondary (n=21) } \\
\cline { 2 - 5 } & Number & Percentage & Number & Percentage \\
\hline Shiny & 30 & 37.97 & 1 & 4.76 \\
\hline Pale & 2 & 2.53 & 0 & 0.00 \\
\hline Normal & 47 & 59.49 & 20 & 95.24 \\
\hline Total & $\mathbf{7 9}$ & $\mathbf{1 0 0 . 0 0}$ & $\mathbf{2 1}$ & $\mathbf{1 0 0 . 0 0}$ \\
\hline
\end{tabular}

Table 1: Laparoscopic examination findings - Ovary color

\begin{tabular}{|c|c|c|c|c|}
\hline \multirow{2}{*}{ Findings } & \multicolumn{2}{|c|}{ Primary $(n=79)$} & \multicolumn{2}{|c|}{ Secondary $(n=21)$} \\
\hline & No. & $\%$ & No. & $\%$ \\
\hline Left blind end & 1 & 1.27 & 0 & 0.00 \\
\hline Left blocked & 1 & 1.27 & 0 & 0.00 \\
\hline Left fimbrial cyst & 1 & 1.27 & 0 & 0.00 \\
\hline Left adhesions & 0 & 0.00 & 1 & 4.76 \\
\hline Left fallopian tube adherent to uterus & 0 & 0.00 & 1 & 4.76 \\
\hline Right fallopian tube adherent to uterus & 1 & 1.27 & 0 & 0.00 \\
\hline Inflamed & 2 & 2.53 & 4 & 19.05 \\
\hline Normal & 73 & 92.41 & 15 & 71.43 \\
\hline Total & 79 & 100.00 & 21 & 100.00 \\
\hline
\end{tabular}

Table 2: Laparoscopic examination findings - Tubes color and appearance 


\begin{tabular}{|l|c|c|c|c|}
\hline \multirow{2}{*}{ Findings } & \multicolumn{2}{c|}{ Primary (n=79) } & \multicolumn{2}{c|}{ Secondary (n=21) } \\
\cline { 2 - 5 } & No. & $\mathbf{\%}$ & No, & $\mathbf{\%}$ \\
\hline $\begin{array}{l}\text { Tubercles on ovary, tubes } \\
\text { and peritoneum }\end{array}$ & 2 & 2.53 & 2 & 9.52 \\
\hline Hydatid cyst of morgagni & 1 & 1.27 & 1 & 4.76 \\
\hline Grade I endometriosis & 2 & 2.53 & 2 & 9.52 \\
\hline Omental adhesions & 2 & 2.53 & 0 & 0.00 \\
\hline
\end{tabular}

Table 3: Laparoscopic findings - Peritoneal findings

\begin{tabular}{|l|c|c|c|c|}
\hline \multirow{2}{*}{ Diagnosis } & \multicolumn{2}{|c|}{ Primary (n=79) } & \multicolumn{2}{c|}{ Secondary (n=21) } \\
\cline { 2 - 5 } & No & $\mathbf{\%}$ & No & $\mathbf{\%}$ \\
\hline PCOS & 15 & 18.99 & 0 & 0.00 \\
\hline Uterine fibroid & 8 & 10.13 & 2 & 9.52 \\
\hline Endometriosis & 5 & 6.33 & 0 & 0.00 \\
\hline PID & 3 & 3.80 & 4 & 19.05 \\
\hline Ovarian cyst & 3 & 3.80 & 2 & 9.52 \\
\hline Endometrial polyp & 2 & 2.53 & 3 & 14.29 \\
\hline PCOS with PID & 2 & 2.53 & 0 & 0.00 \\
\hline Pelvic TB & 2 & 2.53 & 0 & 0.00 \\
\hline Tubal block with PCOS & 2 & 2.53 & 0 & 0.00 \\
\hline Para ovarian cyst & 1 & 1.27 & 0 & 0.00 \\
\hline Unicornuate uterus & 1 & 1.27 & 0 & 0.00 \\
\hline Fibroid with tubal block & 1 & 1.27 & 0 & 0.00 \\
\hline Fimbrial cyst with hypoplastic uterus & 1 & 1.27 & 0 & 0.00 \\
\hline Hyadatid cyst of morgagni & 1 & 1.27 & 0 & 0.00 \\
\hline Arcuate uterus & 0 & 0.00 & 1 & 4.76 \\
\hline Normal & 32 & 40.51 & 9 & 42.86 \\
\hline \multicolumn{1}{|c|}{ Total } & $\mathbf{7 9}$ & $\mathbf{1 0 0 . 0 0}$ & $\mathbf{2 1}$ & $\mathbf{1 0 0 . 0 0}$ \\
\hline
\end{tabular}

\begin{tabular}{|c|c|c|c|c|}
\hline \multirow{2}{*}{ Findings } & \multicolumn{2}{|c|}{ Primary $(n=79)$} & \multicolumn{2}{|c|}{ Secondary $(n=21)$} \\
\hline & No. & $\%$ & No. & $\%$ \\
\hline Hemorrhage & 2 & 2.53 & 1 & 4.76 \\
\hline Infection & 1 & 1.27 & 0 & 0.00 \\
\hline Urinary tract infection & 0 & 0.00 & 1 & 4.76 \\
\hline Absent & 76 & 96.20 & 19 & 90.48 \\
\hline Total & 79 & 100.00 & 21 & 100.00 \\
\hline
\end{tabular}



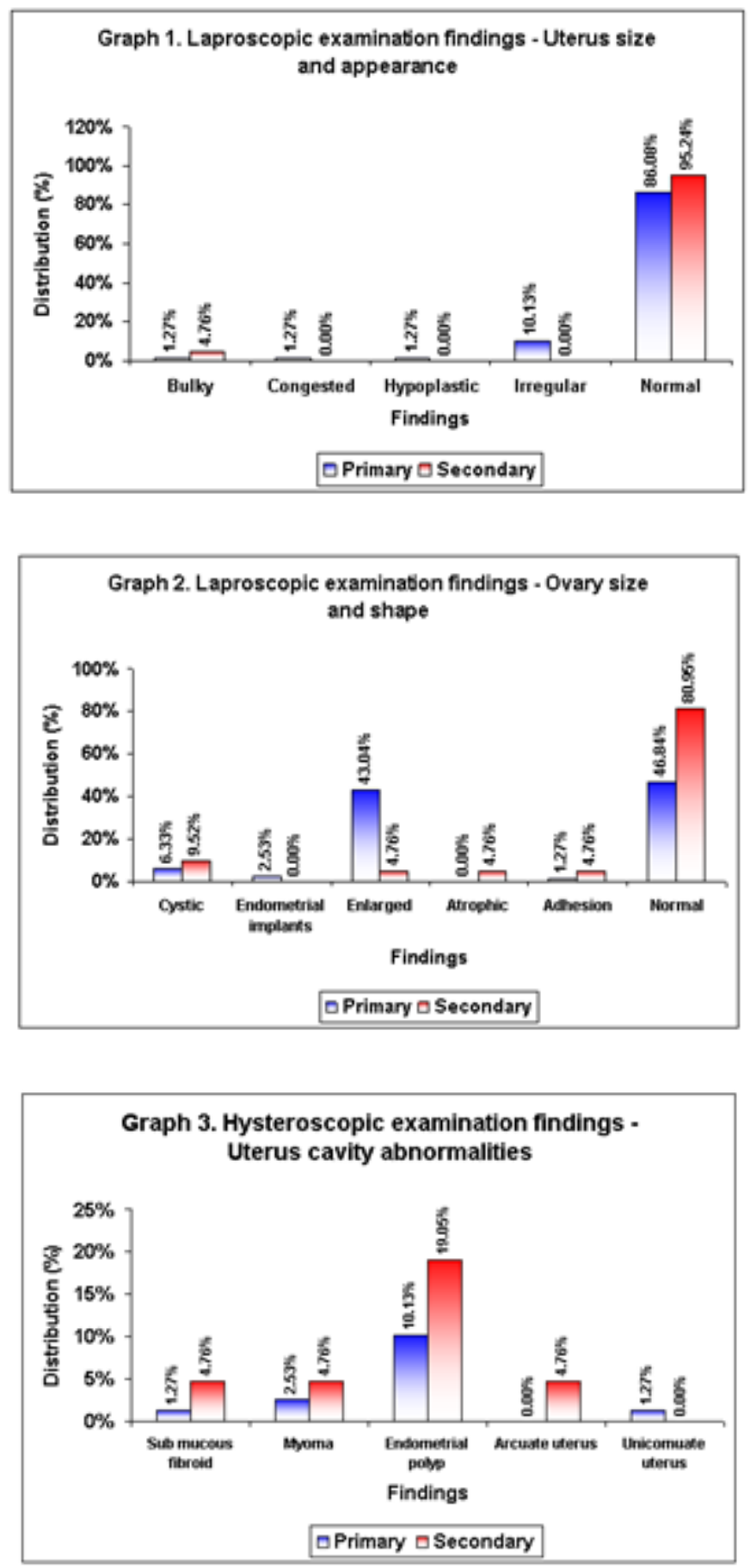


\section{ORIGINAL ARTICLE}



Photograph 1: Instruments

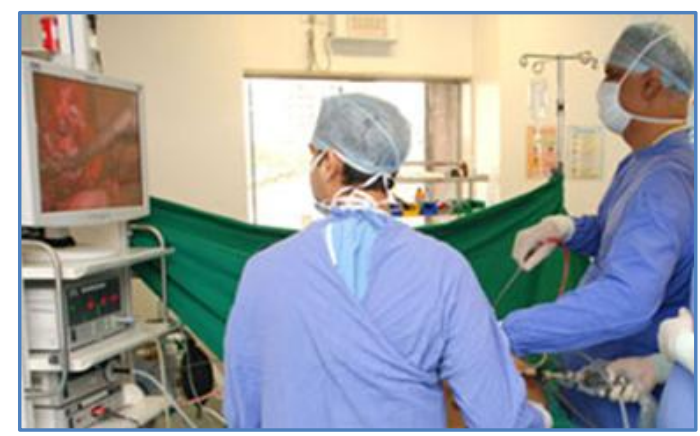

Photograph 3: Laparoscopic surgery



Photograph 5: Caseous nodules

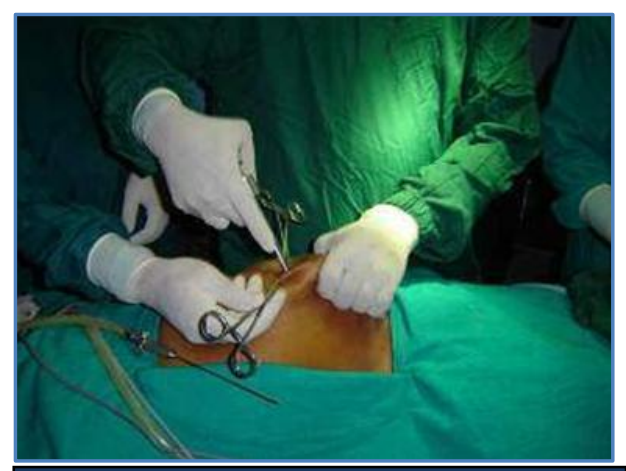

Photograph 2: Trocar insertion

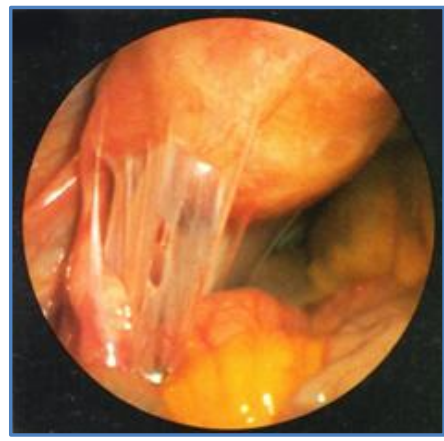

Photograph 4: Adhesions

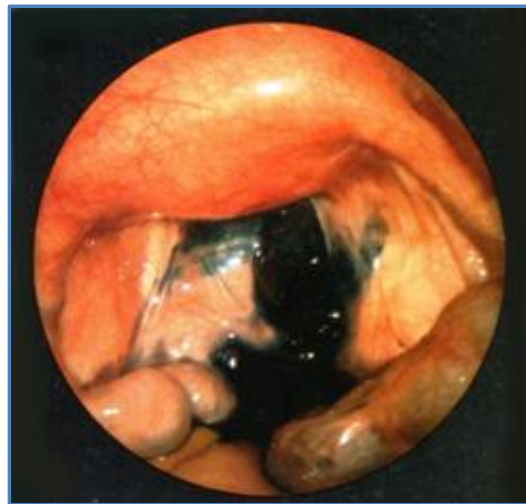

Photograph 6: Chromopertubation 


\section{ORIGINAL ARTICLE}

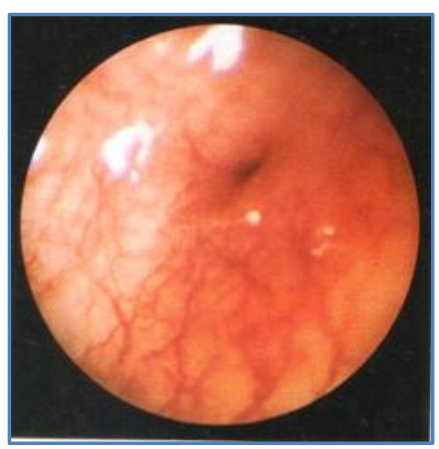

Photograph 7: Closed tubal ostium
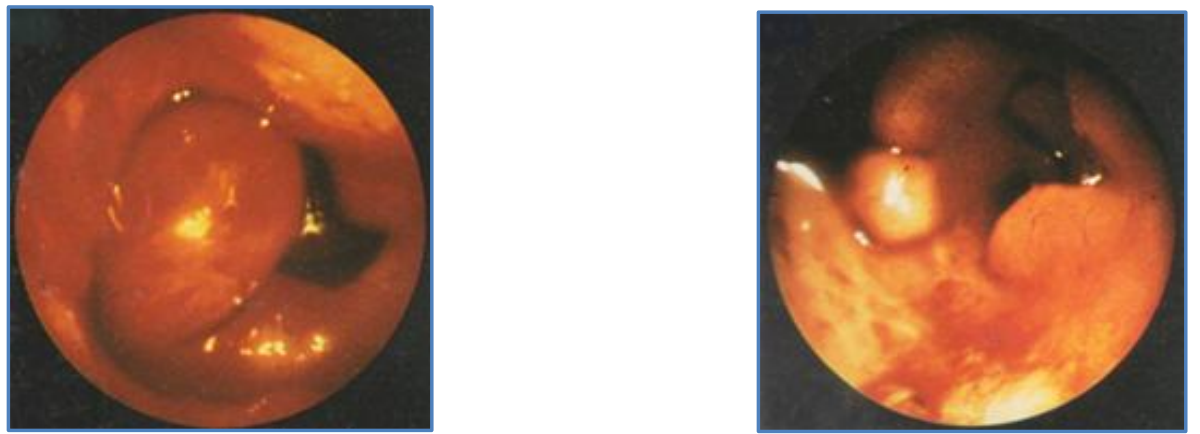

Photograph 8 and 9: Endometrial polyp

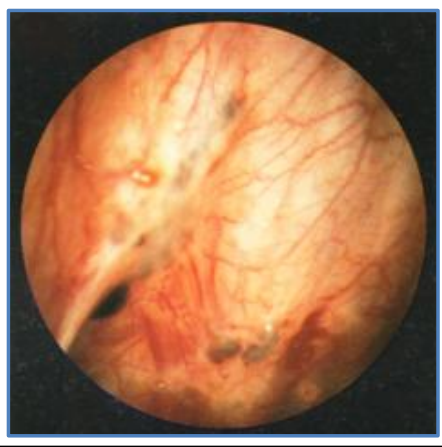

Photograph 10: Endometriosis

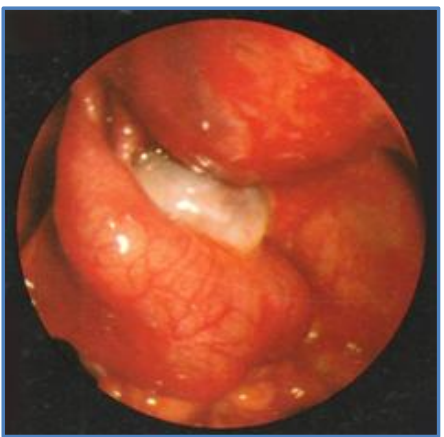

Photograph 12: Inflammed tubes

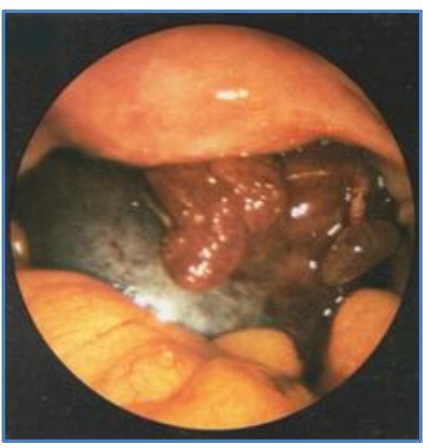

Photograph 11: Hyatid of morgagni

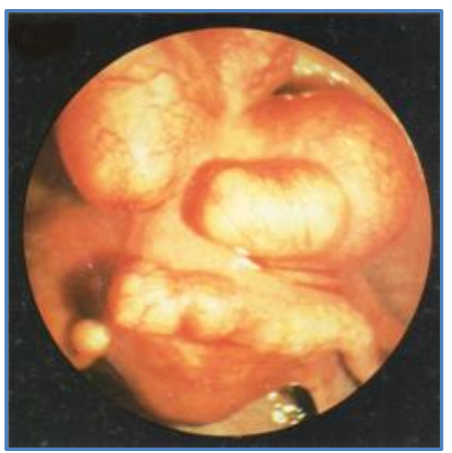

Photograph 13: Multiple fibroids 


\section{ORIGINAL ARTICLE}

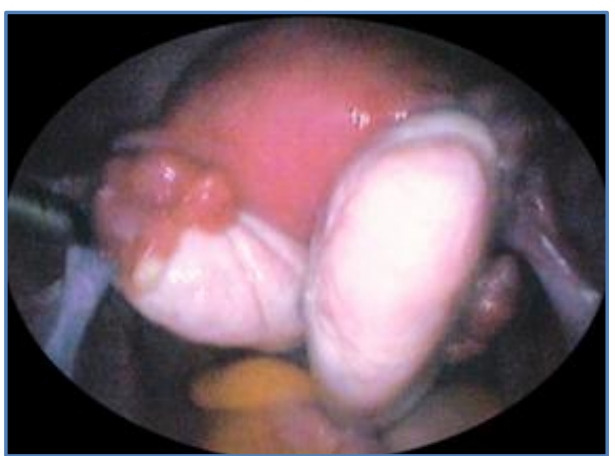

Photograph 14: Polycystic ovary syndrome

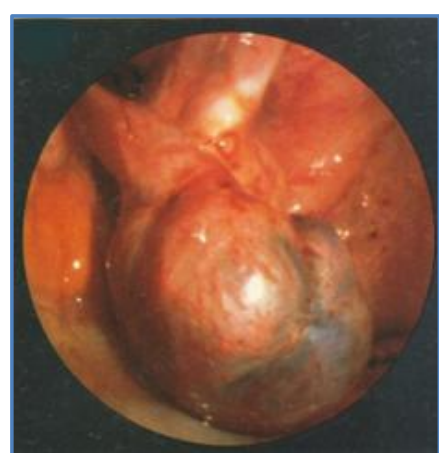

Photograph 15: Hydrosalpinx

\section{AUTHORS:}

1. Dhananjaya Shobha

2. K. N. Madhu

3. Agrawal Amiti

\section{PARTICULARS OF CONTRIBUTORS:}

1. Professor, Department of Obstetrics and Gynecology, JJM Medical College, Davangere.

2. Assistant Professor, Department of Obstetrics and Gynecology, JJM Medical College, Davangere.

3. Post Graduate, Department of Obstetrics and Gynecology, JJM Medical College, Davangere.

\section{NAME ADDRESS EMAIL ID OF THE CORRESPONDING AUTHOR:}

Dr. Shobha Dhananjaya,

Professor, Department of OBG,

JJM Medical College,

Davangere - 577001

E-mail: shobha_dhanu@rediffmail.com

Date of Submission: 03/02/2014.

Date of Peer Review: 04/02/2014.

Date of Acceptance: 14/02/2014.

Date of Publishing: 26/02/2014. 